\title{
Methods of diagnosis and treatment of complex regional pain syndrome: an integrative literature review
}

\author{
Métodos de diagnóstico e tratamento da síndrome da dor regional complexa: uma revisão \\ integrativa da literatura
}

Sheila Bortagaray ${ }^{1}$, Thais Fadel Gonçalves Meulman², Henrique Rossoni Junior ${ }^{3}$, Tiago Perinetto ${ }^{4}$

DOI 10.5935/2595-0118.20190066

\section{ABSTRACT}

BACKGROUND AND OBJECTIVES: The complex regional pain syndrome is characterized by severe pain that affects one extremity of the body, in addition to edema, increased sensitivity to cold and touch, sweating, discoloration and decreased ability to move. This study aimed to identify and analyze the methods of diagnosis and treatment of complex regional pain syndrome. CONTENTS: This is an integrative review of literature conducted in April 2018, which used the electronic database and an academic search engine to select the studies. We sought to complement the survey with manual search of the citations of the primary studies identified. As a search strategy, the authors used the descriptors: "complex regional pain syndrome", "pain", "chronic pain", "diagnosis" and "treatment" in Portuguese and English. A total of 416 references were identified, 11 of which were selected for the present study. Most articles were published in 2016, in English. In general, the articles present the pathophysiology, methods of diagnosis and treatment of complex regional pain syndrome, and it is possible to identify and analyze the consonance and divergence found in the scientific literature. CONCLUSION: The basis for the diagnosis of regional complex pain syndrome remains clinical, and there is no "gold standard" to conduct the diagnosis as there are no accurate imaging indicators or serum markers. The psychological evaluation and the treatment of the disorders, when present, can ensure a better patient's compliance with the treatment instituted.

Keywords: Chronic pain, Complex regional pain syndrome, Diagnosis, Pain, Therapeutics.

Sheila Bortagaray - (Dhttps://orcid.org/0000-0001-9621-3358;

Thais Fadel Gonçalves Meulman - Dhttps://orcid.org/0000-0001-8121-6994;

Henrique Rossoni Junior - Dhttps://orcid.org/0000-0001-8032-554X;

Tiago Perinetto - (Dhttps://orcid.org/0000-0003-4314-1551.

1. Universidade de Caxias do Sul, Caxias do Sul, RS, Brasil.

2. Faculdade Ingá, Araras, SP, Brasil.

3. Universidade Federal de Santa Maria, Santa Maria, RS, Brasil.

4. Universidade Federal do Rio Grande do Sul, Porto Alegre, RS, Brasil.

Submitted on December 27, 2018.

Accepted for publication on May 24, 2019.

Conflict of interests: none - Sponsoring sources: none.

Correspondence to:

Rod. PR 317, 6114 - Parque Industrial 200

87035-510 Maringá, PR, Brasil.

E-mail: sheila.bortagaray@gmail.com

(C) Sociedade Brasileira para o Estudo da Dor

\section{RESUMO}

JUSTIFICATIVA E OBJETIVOS: A síndrome da dor regional complexa é caracterizada por dor intensa que acomete uma extremidade do corpo, além de edema, aumento da sensibilidade ao frio e ao toque, sudorese, alteração de coloração e diminuição da capacidade de movimento. $\mathrm{O}$ objetivo deste estudo foi identificar e analisar os métodos de diagnóstico e tratamento da síndrome da dor regional complexa.

CONTEÚDO: Trata-se de uma revisão integrativa de literatura realizada no mês de abril de 2018, que utilizou bases de dados eletrônicas e um buscador acadêmico para a seleção dos estudos. Buscou-se complementar o levantamento com busca manual nas citaçóes dos estudos primários identificados. Como estratégia de busca dos artigos, utilizou os descritores: "síndrome da dor regional complexa", «dor", "dor crônica”, "diagnóstico" e "tratamento" nos idiomas português e inglês. Foram identificadas 416 referências, sendo 11 artigos selecionados para o presente estudo. A maioria dos artigos foi publicado no ano de 2016 e em inglês. De modo geral, os artigos apresentam a fisiopatologia, os métodos de diagnóstico e de tratamento da síndrome da dor regional complexa, sendo possível identificar e analisar a consonância e a divergência encontrada na literatura científica.

CONCLUSÃO: A base do diagnóstico da síndrome da dor regional complexa permaneceu clínica e não se tem um "padrão ouro" para conduzir o diagnóstico, pois não há indicadores de imagem ou marcadores séricos precisos. A avaliaçáo psicológica e o tratamento de seus distúrbios, quando presentes, garantem melhor adesão do paciente ao tratamento instituído.

Descritores: Diagnóstico, Dor, Dor crônica, Síndrome da dor regional complexa, Terapêutica.

\section{INTRODUCTION}

Complex regional pain syndrome (CRPS), as it is currently called, is an entity that causes great distress, not only for the patient due to the disabling pain but also for health professionals. They are limited in their approach since the pathophysiology of CRPS is not fully understood, and it is difficult to obtain positive treatment results ${ }^{1}$.

Until the last century, CRPS was also called causalgia. In 1877 , causalgia was first described as a chronic painful entity with no neurological cause, accompanied by hitherto unnamed vasomotor changes ${ }^{2}$. Many terminologies have been 
used to designate it, such as minor causalgia, posttraumatic vasomotor disorder, Sudeck atrophy, and shoulder-hand syndrome. Then, it was suggested that all painful diseases associated with vasomotor phenomena, usually preceded by trauma, should be called "reflex sympathetic dystrophy", in which the following characteristics should be present: pain, vasomotor changes of the skin, loss of function of the limb and trophic changes in various stages ${ }^{3}$.

However, the controversy over the diagnosis continued to raise doubts. In 1993, the International Association for the Study of Pain developed a consensus defining the criteria for the diagnosis of this disease ${ }^{4}$. The term "complex regional pain syndrome" or "CRPS" was used to designate the painful regional condition associated with sensory changes resulting from a noxious event. After a trauma, pain is the main symptom and may be associated with abnormal skin coloration, changes in limb temperature, abnormal sudomotor activity, or edema ${ }^{1}$.

By consensus, two types of CRPS were defined: type I, formerly called "reflex sympathetic dystrophy", follows disease or injury that did not directly affect the nerves in the affected limb; and type II, previously called "causalgia”. Type II CRPS differs from type I in that there is a real nerve injury, where the pain is not limited to the injured nerve innervation territory. Approximately $90 \%$ of people with CRPS suffer from type $\mathrm{I}^{5}$.

Patients with CRPS develop severe pain associated with edema, vasomotor instability, joint stiffness, skin lesions, and acute bone atrophy. They often add to the picture of allodynia and hyperalgesia, changes in blood flow and regional sweating; dyscrasia phenomena; changes in the active movement pattern of the affected segments, including the accentuation of physiological tremor; trophic changes of the integument, musculature and subcutaneous cellular tissue and functional disability of the affected segment ${ }^{6}$.

This condition, most often described following acute trauma, surgery, or immobilization of a limb, particularly after evident peripheral nerve injury (causalgia), is also recognized in association with clinical conditions such as diabetic neuropathy, multiple sclerosis, stroke and acute myocardial infarction (sympathetic reflex dystrophy) and is a major cause of disability. Its association with repetitive strain injuries (RSI) and work-related musculoskeletal disorders (WRMSD) is more recent and still little explored ${ }^{7}$. It is noteworthy that CRPS may migrate to another part of the body, such as the opposite foot or arm, and emotional stress often aggravates this pain. In some people, the signs and symptoms of CRPS disappear, while in others, they may continue for months to years ${ }^{4}$.

However, the diagnosis and treatment of CRPS are complex, and probably, for this reason, there are not many studies on these conditions, showing a gap in the scientific literature ${ }^{7,8}$. Considering the importance of knowing the diagnostic methods and treatment types of this clinical condition, this study aimed to identify and analyze the diagnosis and treatment methods of CRPS.

\section{CONTENTS}

This is an integrative review study of the scientific literature developed according to the proposition of two American authors? Therefore, this research was conducted in order to obtain answers to the following question: How does the scientific literature conceptualize and approach the diagnosis methods and type of treatment of CRPS in the national and international scenario? Quantitative or qualitative studies and clinical cases or case reports that analyzed or proposed a theory and/or methodology for the diagnosis and treatment of CRPS were included. Primary studies using an integrative literature review as a methodology to support the diagnosis and treatment of CRPS were excluded; however, these studies were used to support the results. No limits were set on the date of publication or the language of the primary studies.

The search strategy used electronic databases such as LILACS, Science Direct, SCOPUS, Web of Sciences, Pubmed, which includes Medline, Scientific Electronic Library Online (Scielo) digital library, and the academic search engine (Google Scholar). Thus, in addition to databases of indexed scientific publications, gray literature was explored, which prints unpublished literature as technical documents. It was sought to complement the survey with a manual search in the citations of the identified primary studies. It was chosen to use the advanced form with the following keywords in their English or Portuguese versions to verify the title, abstract or subject, depending on the database: "complex regional pain syndrome". "pain”, "chronic pain”, "diagnosis" and "treatment". The Boolean operators adopted in the strategies were "and" and "or". The search was conducted in April 2018.

After identification, the primary studies were selected according to the guiding question and the previously defined inclusion criteria. All studies identified through the search strategy were initially assessed by analyzing the titles and abstracts. In cases where the titles and abstracts were not sufficient to define the initial selection, the full publication was read. Therefore, items that did not correspond to scientific research or were duplicated in the different groups of keywords searched and in the different databases, as well as theses, dissertations, and monographs, were removed from the sample. Figure 1 shows the flowchart of article selection.

After exhaustive reading of the selected material and critical analysis of the data, the captured information was made available in a structured framework to understand and discuss the results according to the diagnosis and treatment proposed in the scientific literature.

During the search in the electronic databases, portal, digital libraries, and the academic searcher, 416 references were identified. Six references were identified by hand searching the citations of primary studies. After the initial exclusion of duplicate references, monographs, dissertations, theses, titles and abstracts that did not apply to the theme, 92 articles were analyzed for eligibility. However, 81 were excluded after reading and registering the full article because it did not address the diagnosis and treatment of CRPS, or because it was a literature review.

So, 11 articles were selected for this study. As gray literature, it used the guidelines proposed by the Brazilian Society for 


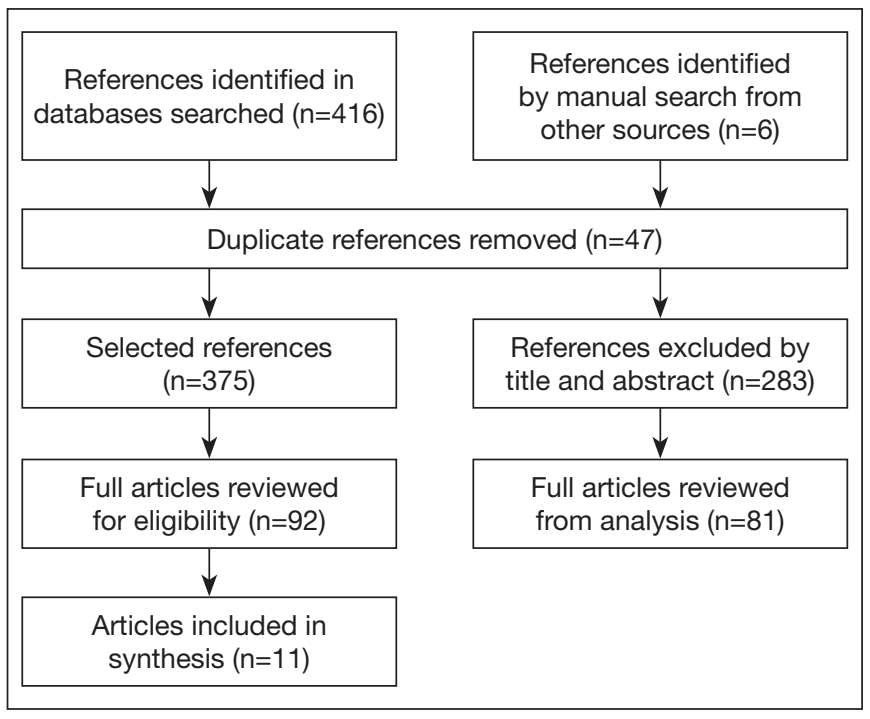

Figure 1. Flowchart of article selection for integrative literature review. Maringá-PR, April 2018

Source: Research Data, 2018.

the Study of Pain ${ }^{10}$. For better visualization of the results, table 1 was elaborated.

Regarding the analysis in the year of publication, it was noted that the studies were published as of 2004, and most of them (7-63.6\%) were published in 2016. The three oldest articles published in the years 2004, 2005, and 2011 are in the Portuguese language and published in Brazilian journals. The re- maining articles published from 2015 on are all international, published in English or Spanish. The predominant language of the articles was English, with seven references (63.6\%).

According to the type of study, it was observed that almost half of the articles are case reports (5-45.5\%) and two (18.2\%) are case series. Four (36.3\%) quantitative studies with descriptive design, case-control, retrospective, and prospective cohort studies were found.

In general, the articles present the pathophysiology of the disease, the diagnostic methods, and the treatment methods of CRPS. The main results and conclusions of the articles selected for the study are discussed below, in two thematic categories, emphasizing the divergences and consonances found in the scientific literature: 1) diagnosis of complex regional pain syndrome; and 2) treatment of CRPS.

\section{DIAGNOSIS OF COMPLEX REGIONAL PAIN SYNDROME}

In this study, it was observed in all articles selected for the study, and in other literature reviews ${ }^{1,5}$ used to support the discussion, that pain is the dominant symptom of CRPS, and trauma is the main etiology of the syndrome. Trauma involves sprains, fractures, dislocations, lacerations, bruises, and strains, as well as prolonged immobilization, tight cast, and surgical trauma $a^{8,15}$. Fractures are the most common incitement events for CRPS, affecting the upper limbs twice as often as the lower limbs.

This disease has been classified in different ways. Currently, it is divided into three stages: acute, which occurs in the first days

Table 1. Selected studies. Maringá-PR, April 2018

\begin{tabular}{|c|c|c|}
\hline Authors & Objectives & Types of studies \\
\hline $\begin{array}{l}\text { Lauretti, Veloso } \\
\text { and Mattos }\end{array}$ & $\begin{array}{l}\text { Report two cases of CRPS in which the application of botulinum toxin A as an adjuvant drug con- } \\
\text { tributed to the functional motor recovery of the affected limb. }\end{array}$ & Case report \\
\hline Azambuja et al. ${ }^{7}$ & $\begin{array}{l}\text { Clinically identify and characterize, in a series of RSI and WRMSD cases, patients with FMS and } \\
\text { CRPS. }\end{array}$ & Case series \\
\hline Artioli et al. ${ }^{8}$ & Describe the results obtained with the physical therapy treatment alone in one patient. & Case report \\
\hline Vas and $\mathrm{Pai}{ }^{11}$ & $\begin{array}{l}\text { Describe the observational results of ultrasound data of muscles and limbs affected with neuro- } \\
\text { pathic pain in } 7 \text { patients and to compare with affected muscles with type } 1 \text { CRPS in } 7 \text { patients. }\end{array}$ & Case report \\
\hline $\begin{array}{l}\text { Bullen, Lang } \\
\text { and Tran }{ }^{12}\end{array}$ & Prospectively determine the incidence of CRPS after foot and ankle fractures. & $\begin{array}{l}\text { Prospective indepen- } \\
\text { dent cohort study }\end{array}$ \\
\hline Salazar ${ }^{13}$ & $\begin{array}{l}\text { Assess the effectiveness of sympathetic stellate ganglion block in the treatment of upper extremity } \\
\text { type I CRPS. }\end{array}$ & Descriptive study \\
\hline Hayashi et al. ${ }^{14}$ & $\begin{array}{l}\text { Report the case of a young woman with type I CRPS who underwent rehabilitation facilitated by } \\
\text { continuous epidural block. }\end{array}$ & Case report \\
\hline $\begin{array}{l}\text { Christophe et } \\
\text { al. }^{15}\end{array}$ & $\begin{array}{l}\text { Describe a comprehensive and quantitative case report showing that: (1) not all patients with chro- } \\
\text { nic CRPS exhibit decreased spatial attention to the affected side, and ( } 2 \text { ) patients may actually } \\
\text { have a substantial, broad, and reliable tendency toward attention on the painful side, similar to } \\
\text { spatial neglect on the healthy side. }\end{array}$ & Case report \\
\hline $\begin{array}{l}\text { Alkosha and } \\
\text { Elkiran }^{16}\end{array}$ & $\begin{array}{l}\text { Determine predictive factors of long-term sympathectomy outcome in patients with type II upper } \\
\text { limb CRPS. }\end{array}$ & Retrospective cohort \\
\hline Albayrak et al. ${ }^{17}$ & $\begin{array}{l}\text { Present } 2 \text { cases that suffered from type I CRPS after stroke and were successfully treated with the } \\
\text { application of pulsed radiofrequency to the dorsal root ganglia. }\end{array}$ & Case series \\
\hline $\begin{array}{l}\text { Kim, Cho and } \\
\text { Lee }^{18}\end{array}$ & $\begin{array}{l}\text { Investigate the effects of frequent long-term ketamine treatment on cognitive function in patients } \\
\text { with CRPS. }\end{array}$ & Case-control \\
\hline
\end{tabular}

$\mathrm{RSI}$ = repetitive strain injury; WRMSD = work-related musculoskeletal disorders; FMS = fibromyalgia syndrome; CRPS = complex regional pain syndrome. Source: Research Data, 2018. 
after injury up to three months; dystrophic, three to six months after its onset; atrophic, from six months to approximately one year from the causal event ${ }^{8}$. Prevention and early diagnosis are believed to be important to slow the development of the disease $^{12}$. However, signs and symptoms are ignored, causing delays in the final diagnosis and early initiation of treatment.

Bullen, Lang e Tran ${ }^{12}$ presented the diagnostic criteria codified by the International Association for the Study of Pain ${ }^{10}$, which were updated in Budapest in 2007 and have since been statistically validated in CRPS populations. For these authors ${ }^{10,12}$, the clinical diagnosis should be based on the following criteria:

1. Continuous pains that are disproportionate to any instigating event;

2. Reporting at least one symptom in three of the following four categories:

2.1 Sensory: reports of hyperesthesia and/or allodynia;

2.2 Vasomotor: reports of temperature asymmetry and/or changes in skin color and/or skin color asymmetry;

2.3 Sudomotor/edema: reports of edema and/or sweating and or sweating asymmetry;

2.4. Motor/trophic: reports of decreased range of motion and/or motor dysfunction (weakness, tremor, dystonia) and/or trophic changes (hair, nail, skin).

3. Must display at least one sign at the time of assessment in two or more of the following categories:

3.1 Sensory: evidence of hyperalgesia (sting) and or allodynia (feeling of light touch and/or temperature and/or deep somatic pressure and/or joint movement);

3.2 Vasomotor: evidence of temperature asymmetry $\left(>1^{\circ} \mathrm{C}\right)$ and/ or changes in skin color and/or asymmetry;

3.3 Sudomotor/edema: evidence of changes in edema and/or sweating and/or sweating asymmetry;

3.4 Motor/trophic: evidence of decreased range of motion and/ or motor dysfunction (weakness, tremor, dystonia) and/or trophic changes (hair, nail, skin).

4. There is no other diagnosis that better explains the signs and symptoms.

According to the authors ${ }^{12,19}$, the criteria updated in Budapest have been shown to improve the specificity and sensitivity of CRPS diagnosis and are the only standardized, internationally recognized, and validated criteria for CRPS diagnosis.

Azambuja et al. ${ }^{7}$ agree with the other authors and emphasize that the diagnosis is eminently clinical, and its primary manifestation is regional pain. There are currently no "objective" examinations with sufficient sensitivity and specificity to be routinely used, thus proposing the following criteria for positive diagnosis of CRPS':

1. Excruciating diffuse regional pain;

2. At least two of the following signs and symptoms:

2.1 Difference in skin color relative to the other limb;

2.2 Edema;

2.3 Temperature difference in the skin relative to the other limb;

2.4 Limitation on active range of motion.

3. Additionally: occurrence or exacerbation of the signs/symptoms described.

Despite these criteria, the diagnosis of CRPS presents several controversies. It should be remembered the difficulties in estab- lishing the diagnosis, as there are no precise image indicators or serum markers ${ }^{8}$, which is one of the most important elements to consider. The clinical classification is based on a better understanding of the pathophysiology of this entity, which dependent factors coexist, such as changes of the peripheral and central nervous systems, the endocrine system, and psychological, environmental, and situational factors ${ }^{13}$. However, the expertise of an expert must be of excellence to make the correct diagnosis. But the criterion of higher weight is given by the absence of another diagnosis that better explains the symptoms and signs.

In a literature review ${ }^{1}$, the authors found that, although the diagnosis of CRPS is clinical, other tests may be requested to confirm or exclude it. A simple radiological test can identify decreased bone calcification, although this change is not specific for CRPS, as bone demineralization may be caused by limb disuse. Electroneuromyography indicates nerve injury in cases of type II CRPS, but it is not useful in the evolutionary control of the disease. Other laboratory imaging tests may be performed: thermography determines the temperature difference between the affected and normal limbs, and plethysmography highlights the differences in perfusion between the limbs. Therapeutic tests are useful to aid in diagnosis by response to a particular substance ${ }^{1}$.

For Vas and Pai ${ }^{11}$, muscle ultrasonography (MUS) is an important research modality used to identify structural lesions of the myofascial system. The authors conducted case studies where MUS in patients with type I CRPS showed loss of muscle architecture and volume in the forearm muscles, particularly in the hand extensors. The striking feature of the findings was intramuscular proliferation of fibrous tapes, giving an appearance of hyperechogenicity compared to the normal limb, indicating loss of myoarchitecture. These changes were seen in muscles that caused difficulty in initiating and sustaining movement (usually flexor digitorum profundus and superficialis of the fingers, but also in other flexor muscles, such as the flexor carpi radialis, the palmaris longus, and the pronator teres). Muscle edema was visualized in a patient with muscle atrophy. However, the marked loss of myocardial architecture in CRPS could explain the severity of motor symptoms in this condition.

Furthermore, it has been found in the literature that several drugs are used to diagnose CRPS, such as guanethidine, phentolamine, and lidocaine, by various techniques such as simple venous infusions and regional blocks. These tests are used to prove whether the sympathetic nervous system is involved in pain genesis and CRPS signs and symptoms, thus helping to make the diagnosis as well as guiding appropriate and effective therapy ${ }^{1}$.

It is noteworthy that no examination was considered a "gold standard" for diagnosis, although several clinical, radiographic, and electrodiagnostic tests have been described. However, from the analysis of these articles, the basis of the diagnosis of this syndrome remains clinical. Early identification and treatment are essential in preventing the progression of CRPS and appear more effective when instituted early in the disease. Broader prospective studies using validated criteria are needed to guide the clinical management of CRPS and would contribute to consensus on a gold standard for CRPS diagnosis. 


\section{TREATMENT OF COMPLEX REGIONAL PAIN SYN- DROME}

Because it is a complex disease, difficult to diagnose, with numerous therapeutic proposals and their varied responses, there is no standard protocol for the treatment of CRPS. In many cases, it is necessary to make associations of techniques for a good result. In this sense, it is believed that patient follow-up should be multidisciplinary and multiprofessional due to the various components involved in the disease. Thus, psychological assessment and treatment of its disorders, when present, ensure better adherence to the treatment instituted. In general, the studied literature indicates that the initial treatment is based on analgesia and intensive and careful physical therapy to avoid pain exacerbation. In the second line of treatment is the use of centrally acting analgesics, regional anesthesia, sympathetic block, desensitization of peripheral nerves, among others. Pharmacological therapies are varied. In addition, tricyclic antidepressants, gabapentin, opioids, and topical capsaicin are associated. In refractory cases, surgery may be used, but its use is very restricted ${ }^{20}$. The main CRPS treatment methods identified in this study will be detailed below:

\section{Stellate ganglion block}

The stellate ganglion is a group of nerves in the neck region. A descriptive study ${ }^{13}$ with 229 patients with type I CRPS in the upper limbs performed stellate ganglion block according to the Nolte-modified Herget technique ${ }^{21}$. For this, it used 1\% lidocaine for the skin papule and $0.25 \%$ bupivacaine twice a week. Once the treatment was performed, the patients remained at least $1 \mathrm{~h}$ in the post-anesthetic recovery room. All patients were trained to perform physical therapy at home. At the end of treatment, high efficacy in symptom relief was found, although $17.9 \%$ of patients returned without finding definitive relief for their disease. In this sense, the author ${ }^{13}$ proposes that a $50 \%$ decrease in pain through stellate ganglion block should be considered as a satisfactory treatment.

\section{Botulinum toxin A}

The reports in the literature on the use of botulinum toxin as an adjunct in functional rehabilitation are initial but encouraging. Lauretti, Veloso and Mattos $^{6}$ used botulinum toxin in two patients with type I CRPS simultaneously during the third stellate ganglion block. A total of 75 IU of botulinum toxin was equitably administered by muscle to the flexor muscles of the affected phalanges and wrist joint of each patient. One week after botulinum toxin A application, patients presented phalanx and wrist relaxation, reported ease of performing passive physical therapy, and pain was rated 2 according to the visual analog scale (VAS) for pain in passive manipulation. After eight months of assessment, the patients presented 70 and $80 \%$ of motor and functional recovery of the affected limb. The patients remained under passive physical therapy for the entire period initially, and later active and were able to integrate again in their routine work.

\section{Ketamine}

CRPS often does not respond to traditional pharmaceutical treatment and is, therefore, a challenge for healthcare professionals. Ketamine, a non-barbiturate anesthetic drug, has recently been introduced as a new therapeutic intervention for pain relief, demonstrating marked reduction in pain and improved cognitive function after short-term treatment in patients with CRPS. The advantages of using ketamine include a rapid onset of action, brief cardiorespiratory depressant effects, and a benign effect on muscle tone and protective airway reflexes. However, given the characteristics of CRPS involving chronic pain, prolonged use may be detrimental. Authors ${ }^{18}$ have shown that repetitive ketamine use provides analgesic effects on CRPS, but its frequent or repetitive use for extended periods may impair the cognitive function. This impairment may occur because ketamine is a non-competitive antagonist of the glutamate N-methyl-D-aspartate receptor, and its repeated use has been associated with reduced function of the prefrontal dopaminergic system, which plays an essential role in cognitive function. Given these factors, frequent long-term ketamine treatment may impair cognitive function in CRPS patients by altering dopaminergic function in the prefrontal cortex.

\section{Epidural anesthesia}

It is used to promote rehabilitation in CRPS patients who cannot support physical programs due to severe pain. Authors ${ }^{14}$ reported the case of a 15-year-old girl diagnosed with type I CRPS who underwent a rehabilitation program facilitating epidural block with $0.15 \%$ ropivacaine. His rehabilitation program included physical therapy and cognitive behavioral therapy. The intensity of the exercise was gradually increased without exacerbation of its symptoms. Finally, she recovered completely after continuous epidural block for 21 days and rehabilitation for 80 days. However, the authors concluded that there was a combination of continuous epidural block and intensive rehabilitation and that this association improved the patient's symptoms.

\section{Physiotherapy treatment}

Physiotherapy, previously used in later phases, has its space and importance increased today ${ }^{14}$. Authors ${ }^{8}$ state that when physiotherapy is mentioned, it is associated with another form of treatment. Therefore, they analyzed the results obtained with the only physiotherapy in a patient with type I CRPS in the acute stage. The patient underwent eight weeks of treatment, with approximately 40 minutes each session, totaling 13 physiotherapy sessions, with her reassessment in the last session. To assess the effects of physiotherapy on CRPS, it was requested not to give any other form of pharmacological treatment or any other kind, just follow-up on CRPS I conditions. Of the analyzed items, those that showed significant improvement were: (1) staining of the skin, (2) decreased edema; (3) improved neuromuscular control. Despite being the rehabilitation of only one individual, the results obtained in this study suggest that physiotherapy alone can contribute to the improvement of this syndrome. 


\section{Sympathectomy}

One of the most effective and popular treatment modalities for type II CRPS is sympathectomy ${ }^{16}$. However, two types of pain associated with type II CRPS should be considered before sympathectomy: sympathetically maintained and independent pain, depending on whether or not the pain responds to the preoperative stellate ganglion block. Although sympathectomy is regarded as the treatment of choice for patients with the first type of pain, it is considered ineffective in the latter. In a study ${ }^{17}$ developed with 53 patients, mean age $47 \pm 7$ years old and $60 \%$ women, included according to the Budapest criteria ${ }^{19}$, sympathectomy proved to be an effective surgical instrument in this specific patient population.

\section{Pulsed radiofrequency}

It is a therapeutic modality that has been used for years for diseases associated with neuropathic pain. Recently, the application of pulsed radiofrequency to the dorsal root ganglia has been used effectively to produce long-term pain relief for neuropathic pain modalities. One study ${ }^{17}$ presented two cases of patients who suffered from type I CRPS after stroke and were successfully treated with the application of pulsed radiofrequency current to the cervical ganglia. Both cases suggest that pulsed radiofrequency is an option that should be considered for the treatment of therapy-resistant type I CRPS patients. Moreover, pulsed radiofrequency is a safer alternative treatment due to its slightly less invasive nature, and the injury produced by the limited and controllable pulsed radiofrequency current.

\section{CONCLUSION}

There was an agreement in the scientific literature regarding the diagnosis and the variety of CRPS treatment methods. It has been found that the basis of the diagnosis of this syndrome remains clinical and there is no "gold standard" to drive the diagnosis as there are no precise image indicators or serum markers. It is currently believed that patient follow-up should be multidisciplinary and multiprofessional due to the various components involved in the disease. Therefore, psychological assessment and treatment of their disorders, when present, ensure better adherence to the treatment instituted. However, early clinical identifi- cation and treatment are essential in preventing the progression of CRPS and appear to be more effective when initiated early.

\section{REFERENCES}

1. Cordon FC, Lemonica L. [Complex regional pain syndrome: epidemiology, pathophysiology, clinical manifestations, diagnostic tests and therapeutic proposals]. Rev Bras Anestesiol. 2002;52(5):618-27. Portuguese.

2. Wolff J. Ueber einen Fall von Ellenbogensgelenks-Reaktion. Arch Chir. 1877;20:771. Bonica JJ. The Management of Pain. Philadelphia: Lea \& Febiger; 1953.

4. Merskey H, Bogduk N. Classification of Chronic Pain. Seattle: IASP Press; 1994.

5. Gaspar AT, Antunes F. [Type I complex regional pain syndrome]. Acta Med Port. 2010;24(6):1031-40. Portuguese.

6. Lauretti GR, Veloso Fdos S, Mattos AL. [Functional rehabilitation and analgesia with botulinum toxin $\mathrm{A}$ in upper limb complex regional pain syndrome type I: case reports]. Rev Bras Anestesiol. 2005;55(2):207-11. Portuguese.

7. Azambuja MI, Tschiedel PS, Kolinger MD, Oliveira PA, Mendes JM, Bassanesi SL. Síndrome miofascial e síndrome de dor regional complexa em pacientes com LER/ DORT atendidos em ambulatório de saúde do trabalhador do SUS - identificação e caracterização clínica dos casos. Rev Bras Med Trab. 2004;2(4):176-84.

8. Artioli DP, Gualberto HD, Freitas DG, Bertolini GR. Tratamento fisioterapêutico na síndrome complexa de dor regional tipo I. Relato de caso. Rev Bras Clin Med. 2011;9(1):83-6

9. Whittemore R, Knafl K. The integrative review: updated methodology. J Adv Nurs. 2005;52(5):546-53.

10. Sociedade Brasileira para o Estudo da Dor. Síndrome de Dor Complexa Regional, 2018 [internet]. Disponível em: http://www.sbed.org.br/lermais_materias.php?cd materias=519. Acesso: 14 jun 2018 .

11. Vas P, Pai R. Musculoskeletal ultrasonography to distinguish muscle changes in complex regional pain syndrome type 1 from those of neuropathic pain: an observational study. Pain Pract. 2016;16(1):E1-E13.

12. Bullen $M$, Lang $C$, Tran P. Incidence of complex regional pain syndrome I following foot and ankle fractures using the Budapest criteria. Pain Med. 2016;17(12):2353-9.

13. Salazar CR. Bloqueo del ganglio estrellado para el tratamiento del síndrome doloroso regional complejo tipo I en miembros superiores. Rev Cubana Anestesiol Reanim. 2016;15(2):145-54.

14. Hayashi K, Nishiwaki K, Kako M, Suzuki K, Hattori K, Sato K, et al. Combination of continuous epidural block and rehabilitation in a case of complex regional pain syndrome. J Nippon Med Sch. 2016;83(6):262-7.

15. Christophe L Delporte L, Revol P, DePaepe A, Rode G, Jacquin-Courtois S, et al. Complex regional pain syndrome associated with hyper attention rather than neglect for the healthy side: a comprehensive case study. Ann Phys Rehabil Med. 2016;59(5-6):294-301.

16. Alkosha HM, Elkiran YM. Predictors of long-term outcome of thoracic sympathectomy in patients with complex regional pain syndrome type 2. World Neurosurg. 2016;92:74-82.

17. Albayrak I, Apiliogullari S, Onal O, Gungor C, Saltali A, Levendoglu F. Pulsed radiofrequency applied to the dorsal root ganglia for treatment of post-stroke complex regional pain syndrome: a case series. J Clin Anesth. 2016:33:192-7.

18. Kim M, Cho S, Lee JH. The effects of long-term ketamine treatment on cognitive function in complex regional pain syndrome: a preliminary study. Pain Med. 2016;17(8):1447-51

19. Harden RN, Bruehl S, Stanton-Hicks M, Wilson PR. Proposed new diagnostic criteria for complex regional pain syndrome. Pain Med. 2007;8(4):326-31.

20. Álvares JF, Paz NM, Viçoso TM, Abrantes WL. Síndrome dolorosa regional complexa: atualizaçāo. Rev Med. 2009;19(3Suppl3):S111-5.

21. Freire E, Camba MA. Técnicas e indicaciones del bloqueo del ganglio estrellado para el tratamiento del dolor. Rev Soc Esp Dolor. 2002;9(5):328-37. 